Article

\title{
Disaccharidase Deficiency in Pediatric Patients with Inflammatory Bowel Disease
}

\author{
Chance S. Friesen ${ }^{1}$, William San Pablo ${ }^{1,2}$, Julie Bass ${ }^{1,2}$, Uttam Garg ${ }^{2,3}$ and Jennifer M. Colombo ${ }^{1,2, *(D)}$ \\ 1 Division of Pediatric Gastroenterology, Children's Mercy Kansas City, Kansas City, MO 64108, USA; \\ csfriesen@cmh.edu (C.S.F.); wsanpablo@cmh.edu (W.S.P.); jabass@cmh.edu (J.B.) \\ 2 School of Medicine, University of Missouri-Kansas City, Kansas City, MO 64108, USA; ugarg@cmh.edu \\ 3 Division of Pathology and Laboratory Medicine, Children's Mercy Kansas City, Kansas City, MO 64108, USA \\ * Correspondence: jmcolombo@cmh.edu; Tel.: +1-816-302-3034
}

check for updates

Citation: Friesen, C.S.; San Pablo, W.; Bass, J.; Garg, U.; Colombo, J.M. Disaccharidase Deficiency in Pediatric Patients with Inflammatory Bowel Disease. Gastrointest. Disord. 2022, 4, 1-7. https://doi.org/ 10.3390 /gidisord 4010001 Academic Editor: Takuji Tanaka

Received: 15 November 2021 Accepted: 6 January 2022

Published: 11 January 2022

Publisher's Note: MDPI stays neutral with regard to jurisdictional claims in published maps and institutional affiliations.

Copyright: (C) 2022 by the authors. Licensee MDPI, Basel, Switzerland. This article is an open access article distributed under the terms and conditions of the Creative Commons Attribution (CC BY) license (https:// creativecommons.org/licenses/by/ $4.0 /)$.

\begin{abstract}
Background: Disaccharidase (DS) deficiencies have been reported in pediatric patients with inflammatory bowel disease (IBD), but the relationship between duodenal inflammation and DS deficiency has not been evaluated outside of lactase deficiency. Methods: This study assessed DS levels and DS deficiencies in pediatric IBD patients who underwent endoscopy with assessment of DS activity. Records were reviewed for IBD subtype, pathology findings, and the results of DS analysis. Results: A total of 136 patients were identified. Overall, 89 (65.4\%) patients had a diagnosis of Crohn's disease (CD), 31 (22.8\%) patients had a diagnosis of ulcerative colitis (UC), and 16 (11.8\%) patients had a diagnosis of indeterminant colitis. Lactase deficiency was identified in $55.9 \%$ of patients, followed by maltase deficiency (19.9\%), sucrase and palatinase deficiency $(14 \%)$, and pandeficiency $(12.5 \%)$. When analyzing only patients with $C D$, patients with duodenitis were more likely to exhibit sucrase deficiency, palatinase deficiency, and pan-deficiency with a trend towards maltase deficiency. Conclusions: The most common DS deficiency was lactase deficiency; however, this was not related to duodenal inflammation. Pediatric patients with CD and duodenal inflammation exhibit DS deficiencies, namely, sucrase, palatinase, and pan-deficiency. Dietary adjustments may be warranted temporarily until duodenal inflammation is healed in patients with CD and duodenitis.
\end{abstract}

Keywords: disaccharidase deficiency; inflammatory bowel disease; ulcerative colitis; Crohn's disease

\section{Introduction}

Upper gastrointestinal tract inflammation is common in pediatric inflammatory bowel disease (IBD) [1-6]. This inflammation is associated with more severe disease and more frequent symptoms including epigastric pain, nausea, vomiting, and diarrhea $[7,8]$. These symptoms may be directly related to duodenal inflammation and/or disaccharidase (DS) deficiency resulting from duodenal inflammation and villous injury. The ability to identify symptom etiology, especially if symptoms are related to DS deficiency, may influence treatment recommendations.

Lactase deficiency has been the most studied DS deficiency in IBD. A recent metaanalysis concluded that lactase deficiency is prevalent among adult patients with Crohn's disease (CD) and small bowel involvement [9]. However, in pediatric patients, the prevalence of lactase deficiency is similar in patients with IBD as compared to patients with chronic abdominal pain [10]. Additionally, lactase deficiency does not seem to be associated with duodenitis in pediatric patients with IBD $[10,11]$. There is a paucity of studies describing DS deficiencies in pediatric patients with IBD. Only one previous study evaluated sucrase and maltase deficiency which were present in a large proportion of pediatric patients with IBD [12]. To our knowledge, a relationship between duodenal inflammation and DS deficiency, other than lactase deficiency, has not been evaluated in pediatric patients with IBD. 
The primary aims of the current study were to (1) assess the frequency of DS deficiencies in pediatric patients with IBD and (2) assess the relationship between DS deficiencies and duodenal inflammation.

\section{Results}

A total of 136 patients diagnosed with IBD and undergoing DS analysis were identified. Overall, 89 (65.4\%) patients had a diagnosis of Crohn's disease (CD), $31(22.8 \%)$ patients had a diagnosis of ulcerative colitis (UC), and $16(11.8 \%)$ patients had a diagnosis of indeterminant colitis. Females accounted for $47.1 \%$ of all patients and did not differ between IBD subtypes. Ages ranged from 3 to 21 years with a mean of $14.2 \pm 3.9$ years. Mean ages did not differ between IBD subtypes. The gastrointestinal tract histologic findings are summarized below (Table 1).

Table 1. Histologic inflammation of the gastrointestinal tract in patients with inflammatory bowel disease.

\begin{tabular}{lc}
\hline Esophagitis & $\mathbf{4 7}(\mathbf{3 4 . 6} \%)$ \\
\hline Gastroesophageal reflux disease & $39(83.0 \%)$ \\
\hline Eosinophilic esophagitis & $8(17.0 \%)$ \\
\hline Gastritis & $\mathbf{9 1 ( 6 6 . 9 \% )}$ \\
\hline Chronic & $54(59.3 \%)$ \\
\hline Chronic active & $21(23.1 \%)$ \\
\hline Eosinophilic & $15(16.5 \%)$ \\
\hline Duodicobacter pylori & $1(1.1 \%)$ \\
\hline Chronic & $38(27.9 \%)$ \\
\hline Chronic active & $5(13.2 \%)$ \\
\hline Eosinophilic & $18(47.4 \%)$ \\
\hline Ileitis & $\mathbf{1 5 ( 3 9 . 5 \% )}$ \\
\hline Colitis & $13(9.6 \%)$ \\
\hline Ileitis + Colitis & $\mathbf{6 7}(\mathbf{4 9 . 3} \%)$ \\
\hline
\end{tabular}

Villous atrophy was found in the duodenum in $4.4 \%$ of patients and did not occur in the absence of inflammation. Duodenitis occurred in $43.2 \%$ of those with ileitis versus $15.6 \%$ of those without ileitis $(p=0.004)$. Duodenitis occurred in $36.1 \%$ of those with colitis versus $14.3 \%$ of those without colitis $(p=0.036)$. Overall, duodenitis was present in $93.8 \%$ of patients with ileocolitis, $50 \%$ of patients with ileitis only, $30.4 \%$ of patients with colitis only, and in no patients with normal lower tract histology.

Lactase deficiency was found in $55.9 \%$ of patients, sucrase deficiency in $14.0 \%$ of patients, maltase deficiency in $19.9 \%$ of patients, palatinase deficiency in $14.0 \%$ of patients, and pan-deficiency in $12.5 \%$ of patients. DS activity levels did not differ between IBD subtypes for lactase $(\mathrm{F}=1.069, p=0.346)$, sucrase $(\mathrm{F}=1.168, p=0.314)$, maltase $(\mathrm{F}=1.497$, $p=0.228)$, or palatinase $(\mathrm{F}=1.929, p=0.149)$. Frequencies of deficiencies did not differ between patients with and without ileitis or between patients with and without colitis. No individual disaccharidase activity levels differed between patients with and without ileitis or between patients with and without colitis. There were no differences in DS deficiency frequency in patients with duodenitis as compared to those without duodenitis (Table 2).

However, patients with duodenitis did have lower sucrase and maltase activity levels when compared with patients without duodenitis (Table 3). 
Table 2. Comparison of the frequency of disaccharidase deficiency in patients with inflammatory bowel disease with duodenitis vs. those without duodenitis.

\begin{tabular}{cccc}
\hline & Duodenitis $(\boldsymbol{n}=\mathbf{3 8})$ & No Duodenitis $(\boldsymbol{n}=\mathbf{9 8})$ & $\boldsymbol{p}$ Value \\
\hline Lactase Deficiency & $57.9 \%$ & $55.1 \%$ & 0.769 \\
\hline Sucrase Deficiency & $21.1 \%$ & $11.2 \%$ & 0.138 \\
\hline Maltase Deficiency & $28.9 \%$ & $16.3 \%$ & 0.098 \\
\hline Palatinase Deficiency & $21.1 \%$ & $11.2 \%$ & 0.138 \\
\hline Pan-deficiency & $21.1 \%$ & $9.2 \%$ & 0.060
\end{tabular}

Data are indicated as frequency; $p$ values were calculated using the chi square test.

Table 3. Comparison of mean disaccharidase activity levels (umol/min/gram protein) in patients with inflammatory bowel disease with duodenitis vs. those without duodenitis.

\begin{tabular}{cccc}
\hline & Duodenitis $(\boldsymbol{n}=\mathbf{3 8})$ & No Duodenitis $(\boldsymbol{n}=\mathbf{9 8})$ & $p$ Value \\
\hline Lactase Activity & $14.1 \pm 12.3$ & $17.1 \pm 15.9$ & 0.294 \\
\hline Sucrase Activity & $40.8 \pm 18.5$ & $49.8 \pm 24.6$ & 0.042 \\
\hline Maltase Activity & $128.8 \pm 47.8$ & $151.0 \pm 57.3$ & 0.036 \\
\hline Palatinase Activity & $8.0 \pm 3.9$ & $9.5 \pm 4.5$ & 0.070 \\
\hline
\end{tabular}

Data are indicated as mean $+/-\mathrm{SD} ; p$ values were calculated using the student's $t$ test.

When analyzing only patients with $\mathrm{CD}$, patients with duodenitis were more likely to exhibit sucrase deficiency, palatinase deficiency, and pan-deficiency with a trend towards maltase deficiency (Table 4).

Table 4. Comparison of the frequency of disaccharidase deficiency in patients with Crohn's disease with duodenitis vs. those without duodenitis.

\begin{tabular}{cccc}
\hline & Duodenitis $(\boldsymbol{n}=\mathbf{4 0})$ & No Duodenitis $(\boldsymbol{n}=\mathbf{9 6})$ & $p$ Value \\
\hline Lactase Deficiency & $57.7 \%$ & $55.6 \%$ & 0.853 \\
\hline Sucrase Deficiency & $23.1 \%$ & $7.9 \%$ & 0.048 \\
\hline Maltase Deficiency & $26.9 \%$ & $11.1 \%$ & 0.062 \\
\hline Palatinase Deficiency & $23.1 \%$ & $7.9 \%$ & 0.048 \\
\hline Pan-deficiency & $23.1 \%$ & $7.9 \%$ & 0.048
\end{tabular}

Data are indicated as frequency; $p$ values were calculated using the chi square test.

In patients with $C D$, there was a trend towards lower sucrase $(42.0 \pm 18.5 \mathrm{umol} / \mathrm{min} / \mathrm{gram}$ protein vs. $51.8 \pm 24.4 \mathrm{umol} / \mathrm{min} /$ gram protein; $p=0.069)$ and maltase $(131.7 \pm 50.1 \mathrm{umol} / \mathrm{min} / \mathrm{gram}$ protein vs. $156.1 \pm 54.3 \mathrm{umol} / \mathrm{min} /$ gram protein; $p=0.051$ ) activity levels in patients with duodenitis as compared with those without duodenitis (Table 5).

Table 5. Comparison of mean disaccharidase activity levels (umol/min/gram protein) in patients with Crohn's disease with duodenitis and without duodenitis.

\begin{tabular}{cccc}
\hline & Duodenitis $(\boldsymbol{n}=\mathbf{4 0})$ & No Duodenitis $(\boldsymbol{n}=\mathbf{9 6})$ & $p$ Value \\
\hline Lactase Activity & $12.4 \pm 9.6$ & $16.9 \pm 15.9$ & 0.185 \\
\hline Sucrase Activity & $42.0 \pm 18.5$ & $51.8 \pm 24.4$ & 0.069 \\
\hline Maltase Activity & $131.7 \pm 50.1$ & $156.1 \pm 54.3$ & 0.051 \\
\hline Palatinase Activity & $8.3 \pm 4.2$ & $10.1 \pm 4.7$ & 0.097 \\
\hline
\end{tabular}

Data are indicated as mean $+/-$ SD; $p$ values were calculated using the student's $t$ test. 


\section{Discussion}

In the current study, DS deficiency was common among pediatric patients with IBD, and it did not differ by IBD subtype. Lactase deficiency was the most common DS deficiency identified in the study population. Lactase has been more extensively studied than other DS deficiencies. A meta-analysis, based almost exclusively on adult studies, concluded that IBD was associated with lactose malabsorption but only in CD patients with small bowel involvement [9]. Decreased duodenal lactase levels have been correlated with disease activity in adults [13]. In youth, the prevalence of lactase deficiency is similar in patients with IBD as compared to patients with chronic abdominal pain $[10,11]$. In contrast to the adult studies, Pfefferkorn and colleagues found no significant association between duodenitis and lactase deficiency in pediatric patients [10]. Likewise, we found no difference in lactase activity levels between patients with and without duodenitis.

In this study, duodenitis was identified in $27.9 \%$ of patients and was primarily identified as chronic active inflammation or eosinophilic inflammation. Villous atrophy was rare. Duodenitis was associated with ileal and colonic inflammation, being present in $93.8 \%$ of patients with ileocolitis, $50 \%$ of patients with ileitis only, $30.4 \%$ of patients with colitis only, and in no patients with normal lower tract histology. An increase in duodenitis has previously been reported in youth with IBD and has been associated with cryptitis but rarely with granulomas [14]. CD-associated duodenitis has been found to have increased eosinophils and less villous blunting than that seen in celiac disease [6].

In patients with $C D$, duodenitis was associated with lower sucrase and maltase activity levels. Duodenitis was associated with increased frequencies of sucrase deficiency, palatinase deficiency, and pan-deficiency with a trend towards maltase deficiency. Two previous studies have shown a decrease in sucrase activity in the jejunum of adults with IBD, particularly CD $[15,16]$. Only one previous study assessed the prevalence of DS deficiencies in youth with IBD. Wiecek and colleagues reported sucrase deficiency in $40 \%$ of 15 patients with CD and $45 \%$ of 20 patients with UC [12]. Maltase deficiency was found in 33\% of CD patients and $15 \%$ of UC patients [12]. An association between sucrase deficiency and inflammation is certainly plausible, as inflammatory cytokines can cause specific reductions in mucosal sucrase-isomaltase enzyme [17].

With sucrase deficiency, it is not surprising to also see palatinase deficiency, a trend towards maltase deficiency, and possibly even pan-deficiency as sucrase-isomaltase accounts for nearly all palatinase activity and about $80 \%$ of maltase activity on the assay [18,19]. A previous pediatric study found significant correlations of sucrase with both palatinase and maltase activity levels [20]. Given the high frequency of lactase deficiency, combined lactase and sucrase could be common and may account for pan-deficiency. It has been suggested that pan-deficiency may be an artifact of obtaining the biopsy from the wrong location or of the improper handling and processing of the biopsy. However, in a prospective study, Chumpitazi and colleagues found pan-deficiency to be common in patients where great care was taken regarding biopsy location and processing [21].

In this study, inflammation was common in the esophagus, stomach, and duodenum of children and adolescents with IBD. Esophagitis was present in $37 \%$ of the patients. This was primarily esophagitis consistent with gastroesophageal reflux. However, $6 \%$ of the total patients had biopsies consistent with eosinophilic esophagitis. A previous population study demonstrated an increased prevalence of eosinophilic esophagitis in patients with IBD [22]. Gastritis was the most common upper gastrointestinal tract pathology finding, being present in nearly three-fourths of patients. This was the only finding which occurred more often in CD patients as compared with UC patients. The inflammation was primarily chronic or chronic active. This is consistent with previous studies demonstrating gastritis in over half of the CD patients, particularly in children and adolescents [2-6].

The strength of the current study is the relatively large sample size of youth with IBD undergoing endoscopy with biopsy for pathologic assessment and DS analysis. Additionally, all DS samples were measured in a single commercial lab, and DS activity levels were analyzed as both mean levels and as dichotomous variables (normal vs. abnormal). 
The potential weakness of this study is selection bias, as all patients were pre-selected and very few of the patients had definitive Crohn's duodenitis. The decision to obtain DS testing in patients is based on individual clinician preference; clinical symptoms are poor predictors of DS deficiency and symptoms would not be expected to affect the assessment of relationships between inflammation and DS activity [21,23].

We found that the most common DS deficiency in this pediatric cohort was lactase deficiency; however, lactase deficiency was not related to duodenal inflammation. Overall, the frequencies of DS deficiency did not differ between CD and UC. Pediatric patients with CD and duodenal inflammation exhibited DS deficiencies, namely, sucrase, palatinase, and pan-deficiency. Additionally, it is possible that small intestinal bacterial overgrowth could account for some of the alterations. Well-designed prospective studies will be necessary to determine if DS deficiencies are related to small bowel bacterial overgrowth and inflammation and could contribute to symptoms in pediatric patients with IBD, specifically CD. Furthermore, it is important to investigate whether the DS deficiencies resolve with treatment of duodenitis, because dietary changes could be considered, temporarily, while duodenal inflammation is healing.

\section{Materials and Methods}

\subsection{Study Design}

This was a retrospective, single-site study assessing all patients with IBD less than 22 years of age who underwent endoscopy with assessment of DS activity between 2016 and 2019.

\subsection{Data Collection}

Medical records were reviewed for patient demographics, IBD sub-type diagnosis (Crohn's disease, ulcerative colitis, or indeterminate colitis), pathology findings, and results of DS analysis. All biopsies were previously assessed as part of standard clinical care by board-certified pediatric pathologists. Pathology reports were reviewed for the presence of esophagitis, gastritis, duodenitis, ileitis, and colitis.

Esophagitis: Classified as gastroesophageal reflux disease if the peak eosinophil density was $<15 /$ high power field (hpf) or as eosinophilic esophagitis if the peak eosinophil density was $\geq 15 / \mathrm{hpf}$.

Gastritis: Classified as chronic (presence of increased lymphocytes and/or plasma cells), chronic active (presence of chronic inflammation and neutrophils), or eosinophilic (presence of increased eosinophils $>25 / \mathrm{hpf}$ ). The presence of Helicobacter pylori in gastric biopsies was recorded.

Duodenitis: Classified as chronic (presence of increased lymphocytes and/or plasma cells), chronic active (presence of chronic inflammation and neutrophils), or eosinophilic (presence of increased eosinophils $>25 / \mathrm{hpf}$ ).

DS analysis: Biopsies were obtained from the second portion of the duodenum distal to the ampulla. The tissue samples for DS testing were immediately placed on ice and time stamped. The tissue was transferred to the lab within $30 \mathrm{~min}$ and then flash-frozen in the lab. The frozen tissue was sent to Mayo laboratories, Rochester, MN, USA the same day from where the samples were forwarded to Joli Diagnostics, Inc. Laboratories, Williamsville, NY, USA for DS analysis. All DS analyses were performed utilizing the modified Dahlqvist method to determine enzyme activity levels.

Both actual DS activity levels and whether DS levels were normal or abnormal per laboratory standard values were recorded.

Normal values:

- $\quad$ Lactase > $15 \mathrm{umol} / \mathrm{min} /$ gram protein;

- Sucrase $>25 \mathrm{umol} / \mathrm{min} /$ gram protein;

- Maltase > $100 \mathrm{umol} / \mathrm{min} /$ gram protein;

- Palatinase $>5 \mathrm{umol} / \mathrm{min} /$ gram protein. 


\subsection{Data Analysis}

All statistical analyses were performed with SPSS version 23 (SPSS, Inc.; Chicago, IL, USA). Frequencies of DS deficiency were compared for patients with inflammatory bowel disease with and without duodenitis by chi square analysis. Comparison of mean disaccharidase activity levels in patients with inflammatory bowel disease with and without duodenitis was conducted by student's $t$ test. Frequencies of DS deficiency were compared for patients with Crohn's disease with and without duodenitis by chi square analysis. Comparison of mean disaccharidase activity levels in patients with Crohn's disease with and without duodenitis was conducted by student's $t$ test. A $p$ value $<0.05$ was considered significant.

Author Contributions: Conceptualization, C.S.F., W.S.P., J.B., U.G. and J.M.C.; methodology, C.S.F., W.S.P., U.G. and J.M.C.; validation, C.S.F., W.S.P. and J.M.C.; formal analysis, C.S.F. and J.M.C., investigation, C.S.F., W.S.P., J.B., U.G. and J.M.C.; data curation, C.S.F., W.S.P. and J.M.C.; writing-original draft preparation, C.S.F. and J.M.C.; writing-review and editing, C.S.F., W.S.P., J.B., U.G. and J.M.C.; supervision, J.M.C. All authors have read and agreed to the published version of the manuscript.

Funding: This research received no external funding.

Institutional Review Board Statement: The study was approved by the Institutional Review Board (IRB) Children's Mercy Kansas City (IRB: STUDY00000989; Initial Approval: 11/19/2019). It was performed in accordance with the Declaration of Helsinki. Informed consent/assent was waived by the IRB for this retrospective study.

Informed Consent Statement: Informed consent/assent was waived by the IRB.

Data Availability Statement: The data presented in this study are available on request from the corresponding author.

Conflicts of Interest: The authors declare no conflict of interest.

\section{References}

1. Van Limbergen, J.; Russell, R.K.; Drummond, H.E.; Aldhous, M.C.; Round, N.K.; Nimmo, E.R.; Smith, L.; Gillett, P.M.; McGrogan, P.; Weaver, L.T.; et al. Definition of Phenotypic Characteristics of Childhood-Onset Inflammatory Bowel Disease. Gastroenterology 2008, 135, 1114-1122. [CrossRef] [PubMed]

2. Sonnenberg, A.; Melton, S.D.; Genta, R.M. Frequent occurrence of gastritis and duodenitis in patients with inflammatory bowel disease. Inflamm. Bowel Dis. 2011, 17, 39-44. [CrossRef] [PubMed]

3. Genta, R.M.; Sonnenberg, A. Non-Helicobacter pylori gastritis is common among paediatric patients with inflammatory bowel disease. Aliment. Pharmacol. Ther. 2012, 35, 1310-1316. [CrossRef] [PubMed]

4. Hummel, T.Z.; Kate, F.J.T.; Reitsma, J.B.; Benninga, M.A.; Kindermann, A. Additional Value of Upper GI Tract Endoscopy in the Diagnostic Assessment of Childhood IBD. J. Pediatr. Gastroenterol. Nutr. 2012, 54, 753-757. [CrossRef]

5. Park, J.H.; Nam, H.N.; Lee, J.-H.; Hong, J.; Yi, D.Y.; Ryoo, E.; Jeon, I.S.; Tchah, H. Characteristics of Upper Gastrointestinal Tract Involvement in Korean Pediatric Crohn's Disease: A Multicenter Study. Pediatr. Gastroenterol. Hepatol. Nutr. 2017, $20,227-235$. [CrossRef]

6. Abuquteish, D.; Putra, J. Upper gastrointestinal tract involvement of pediatric inflammatory bowel disease: A pathological review. World J. Gastroenterol. 2019, 25, 1928-1935. [CrossRef]

7. Crocco, S.; Martelossi, S.; Giurici, N.; Villanacci, V.; Ventura, A. Upper gastrointestinal involvement in paediatric onset Crohn's disease: Prevalence and clinical implications. J. Crohn's Colitis 2012, 6, 51-55. [CrossRef]

8. Castellaneta, S.P.; Afzal, N.A.; Greenberg, M.; Deere, H.; Davies, S.; Murch, S.H.; Walker-Smith, J.A.; Thomson, M. Diagnostic Role of Upper Gastrointestinal Endoscopy in Pediatric Inflammatory Bowel Disease. J. Pediatr. Gastroenterol. Nutr. 2004, 39, $257-261$. [CrossRef]

9. Szilagyi, A.; Galiatsatos, P.; Xue, X. Systematic review and meta-analysis of lactose digestion, its impact on intolerance and nutritional effects of dairy food restriction in inflammatory bowel diseases. Nutr. J. 2015, 15, 67. [CrossRef]

10. Pfefferkorn, M.D.; Fitzgerald, J.F.; Croffie, J.M.; Gupta, S.K.; Corkins, M.; Molleston, J.P. Lactase Deficiency: Not More Common in Pediatric Patients with Inflammatory Bowel Disease Than In Patients With Chronic Abdominal Pain. J. Pediatr. Gastroenterol. Nutr. 2002, 35, 339-343. [CrossRef]

11. Kirschner, B.; DeFavaro, M.V.; Jensen, W. Lactose Malabsorption in Children and Adolescents with Inflammatory Bowel Disease. Gastroenterology 1981, 81, 829-832. [CrossRef]

12. Wiecek, S.; Wos, H.; Radziewicz-Winnicki, I.; Komraus, M.; Grzybowska-Chlebowczyk, U. Disaccharidase activity in children with inflammatory bowel disease. Turk. J. Gastroenterol. 2014, 25, 185-191. [CrossRef] 
13. Von Tirpitz, C.; Kohn, C.; Steinkamp, M.; Geerling, I.; Maier, V.; Möller, P.; Adler, G.; Reinshagen, M. Lactose intolerance in active Crohn's disease: Clinical value of duodenal lactase analysis. J. Clin. Gastroenterol. 2002, 34, 49-53. [CrossRef]

14. Hardee, S.; Alper, A.; Pashankar, D.S.; Morotti, R.A. Histopathology of Duodenal Mucosal Lesions in Pediatric Patients with Inflammatory Bowel Disease: Statistical Analysis to Identify Distinctive Features. Pediatr. Dev. Pathol. 2014, 17, 450-454. [CrossRef]

15. Arvanitakis, C. Abnormalities of Jejunal Mucosal Enzymes in Ulcerative Colitis and Crohn's Disease. Digestion 1979, 19, 259-266. [CrossRef] [PubMed]

16. Dunne, W.T.; Cooke, W.T.; Allan, R.N. Enzymatic and morphometric evidence for Crohn's disease as a diffuse lesion of the gastrointestinal tract. Gut 1977, 18, 290-294. [CrossRef] [PubMed]

17. Ziambaras, T.; Rubin, D.C.; Perlmutter, D.H. Regulation of Sucrase-Isomaltase Gene Expression in Human Intestinal Epithelial Cells by Inflammatory Cytokines. J. Biol. Chem. 1996, 271, 1237-1242. [CrossRef]

18. Robayo-Torres, C.C.; Diaz-Sotomayor, M.; Hamaker, B.R.; Baker, S.S.; Chumpitazi, B.P.; Opekun, A.R.; Nichols, B.L. 13C-LabeledStarch Breath Test in Congenital Sucrase-isomaltase Deficiency. J. Pediatr. Gastroenterol. Nutr. 2018, 66, S61-S64. [CrossRef] [PubMed]

19. Burke, M. Carbohydrate Intolerance and Disaccharidase Measurement-A Mini-Review. Clin. Biochem. Rev. 2019, 40, 167-174. [CrossRef]

20. Cohen, S.A.; Oloyede, H.; Gold, B.D.; Mohammed, A.; Elser, H.E. Clinical Characteristics of Disaccharidase Deficiencies among Children Undergoing Upper Endoscopy. J. Pediatr. Gastroenterol. Nutr. 2018, 66, S56-S60. [CrossRef] [PubMed]

21. Chumpitazi, B.P.; Robayo-Torres, C.C.; Tsai, C.M.; Opekun, A.R.; Baker, S.S.; Nichols, B.L.; Gilger, M.A. Demographic and Clinical Correlates of Mucosal Disaccharidase Deficiencies in Children with Functional Dyspepsia. J. Pediatr. Gastroenterol. Nutr. 2018, 66, S52-S55. [CrossRef] [PubMed]

22. Fan, Y.C.; Steele, D.; Kochar, B.; Arsene, D.; Long, M.D.; Dellon, E.S. Increased Prevalence of Esophageal Eosinophilia in Patients with Inflammatory Bowel Disease. Inflamm. Intest. Dis. 2018, 3, 180-186. [CrossRef] [PubMed]

23. El-Chammas, K.; Williams, S.E.; Miranda, A. Disaccharidase Deficiencies in Children with Chronic Abdominal Pain. J. Parenter. Enter. Nutr. 2016, 41, 463-469. [CrossRef] [PubMed] 